\title{
Determinants and Dimensions of Household Food Insecurity in Dire Dawa Town, Ethiopia
}

\author{
Aschalew Feleke ${ }^{1}$ and Ayalneh Bogale ${ }^{2 *}$ \\ 1 World Food Program, P O Box 843, Dire Dawa, Ethiopia \\ ${ }^{2}$ Haramaya University, P O Box 170, Haramaya University, Ethiopia
}

\begin{abstract}
Based on primary data collected from 200 household in 2005, this study scrutinizes determinants and the extent of food insecurity in Dire Dawa town. A binary logit model has identified household size, daily income and proportion of expenditure on food, education of household head, sex of household head, access to credit and marital status of the household as significant determinants of food insecurity in the study area. The FGT index result has revealed that $43 \%$ of the sampled households cannot meet the daily recommended caloric requirement with a food insecurity gap of $13 \%$. The findings call for action-based advocacy on family planning to curb population growth, provision of technical training to the unemployed that enhances job creativity and competitiveness on the market, access to credit for the needy with proper targeting criterion and expansion of both formal and informal education.
\end{abstract}

Keywords: Food Security; FGT Index; Logit Model; Dire Dawa

\section{Introduction}

No developing country can afford to ignore the phenomenon of urbanization which will be one of the strongest social forces in coming years especially in developing countries. High rates of urbanization mean that urban food insecurity and malnutrition are concerns even for regions like Africa and Asia where current levels of urbanization are relatively low (Engle et al., 1998).

The level of urbanization in Ethiopia reached $17 \%$ in 2002. However, this level is expected to reach nearly $30 \%$ by the year 2020 as the urban areas are currently growing at around $6 \%$ per year. Slow economic growth and the low level of investments in urban centers combined with high population growth have resulted in high rates of unemployment and the inaccessibility and inadequacy of existing services for low income groups which further exacerbated urban poverty (FDRE, 2002).

Welfare monitoring based poverty analysis of Ethiopia showed that the depth and severity of consumption poverty showed an improvement between 1995/96 and $1999 / 2000$ in rural areas while a slight deterioration was observed in urban areas (MoFED, 2002). The same study revealed that, during the same period, the calorie intake per adult per day in urban Dire Dawa was 1831 and 1929 kilocalories (kcal), respectively, which is below the minimum requirement of $2100 \mathrm{kcal}$. Considering an intake of $2100 \mathrm{kcal}$ per person per day and the minimum cost prevailing in each location, households with insufficient purchasing power in Dire Dawa were estimated to constitute $47 \%$ of the total population (MoPED, 1994).

The CSA (1999) report indicated that the population growth rate in urban Dire Dawa with the medium variant was about 4.1 for the period between 2005 and 2010 . With regard to urban unemployment, CSA (2004) report revealed that the unemployment rate of urban Ethiopia in 2004 was $22.9 \%$ and the rate was highest in the urban areas of Dire Dawa (33.5\%) followed by Addis Ababa $(22.1 \%)$.

The increase in urban population outstrips the capacity of the city to provide employment opportunities because it cannot absorb all the additional supply of labor coming

*Corresponding author. E-mail: ayalnehb@yahoo.com from other areas. Although $74 \%$ of the regional population resides in urban Dire Dawa, the ear-tagged food security budget which was allocated for the Dire Dawa Administration Council has never been allocated for the urban areas employment generation activity. The perception of policy makers and other development agents that rural conditions are much worse than urban ones does not mean that resources should not be directed to the urban poor. The preparation and implementation of different policies to improve the livelihood and food security situation based only on past research findings might ultimately lead to erroneous outcomes because of the fact that socio-cultural, political and economic features can change over time, especially in the urban setting. In view of the above background, the specific objectives of this study were (1) to scrutinize the food insecurity situation and identify its determinants and (2) to examine the extent and severity of the food insecurity gap and its severity in Dire Dawa town.

\subsection{Measurement and Indicators of Food Security}

Measurement is necessary at the outset of any development project to identify the food insecure, to assess the severity of their food shortfall, and to characterize the nature of their insecurity (Hoddinott, 2001). There is no single indicator that best measures household food security, so several indicators are being used. One common indicator is caloric adequacy (Habicht and Pelletier, 1990; Payne, 1990; Maxwell and Frankenberger, 1992; Kennedy et al., 1994; Maxwell, 1996; Chung et al., 1997). This measure captures food sufficiency in terms of quantity but does not address the quality of the diet or issue of vulnerability or sustainable access. The traditional approach of measuring food security using dietary intakes has been to select an optimal caloric intake based on a recommended daily allowance for the equivalent of a moderately active adult and compare it to observed household caloric intake per adult equivalent (Maxwell et al., 2000).

Comparison of methods to measure the state of food insecurity at household level in terms of costs, time requirement, skill and susceptibility to misreporting among four outcome indicators namely individual intake, 
household calorie requisition, dietary diversity and index of coping strategies and household caloric acquisition is found to be a better measurement (Hoddinott, 2001).

Household food security in urban areas primarily depends on the level of income, the prices of food and other consumer goods on which the households allocate outlay. Households with larger family size, less literate and older household heads are more likely to fall into poverty than those with smaller family size, more literate and younger household heads (MoPED, 1994; MoFED, 2002).

Dire Dawa is located in a food deficit region of Ethiopia, the result of which means prices of food grains and other food items are high almost throughout the year. The gap between the low income and other income groups with respect to percent of expenditure on food is narrow, probably reflecting the unsatisfied food demand by the urban community in Dire Dawa. The relative prices of food items are higher compared to other towns such as Jimma, Bahir Dar and Awassa. It may, therefore, be expected that the real income of households in Dire Dawa is lower, the result of which is the affordability by households to purchase food reduced (MoPED, 1994).

\section{Materials and Methods}

\subsection{Description of the Study Area}

Dire Dawa town, located in the eastern part of the country, has an estimated total land area of $39.54 \mathrm{~km}^{2}$. It is located $515 \mathrm{~km}$ east of Addis Ababa between Addis Ababa and Djibouti. Its altitude is about 1200 meters above sea level. Dire Dawa has bimodal rainfall pattern with short rain season from March to April and main rain season from August to mid September. Dire Dawa has an annual rainfall of about $604 \mathrm{~mm}$ and mean annual temperature of $24.8{ }^{\circ} \mathrm{C}$.

Dire Dawa town has an estimated population of 204,244 of which the female population comprises $52.3 \%$. The average household size and sex ratio, defined as number of males per 100 females, is 4.5 and 91.4, respectively. Other demographic indicators revealed an economic activity rate of 48.2, economic dependency ratio of 1.34 and unemployment rate of 33.5 (CSA, 2004).

\subsection{Sampling and Data Collection}

The primary data source for this research was the Dire Dawa urban households' socio economic data collected by undertaking a survey of 200 households. Three stages stratified random sampling technique with probability proportional to size sampling was employed to draw a total of five kebeles and 200 households. At the first stage, Dire Dawa kebeles were stratified into two strata based on wealth ranking of the urban kebeles, each having ten and fifteen kebeles. At the second stage, probability sampling was employed to draw two kebeles from one strata and three from the remaining one. Finally, a total of 200 households were randomly selected from representative kebeles by using probability proportional to size sampling procedure. The sample frame used was a registered household list collected through census by Population and Vital Statistics Office of the Administration Council.

\subsection{Methods of Data Analysis}

Quantities of food commodity consumed by the household during the past seven consecutive days were collected by survey questionnaire and then converted to their kilocalorie equivalent using Food Composition Table for Use in Ethiopia (ENHRI, 1998). Moreover, variations in energy requirements in terms of age and sex of household members were counterbalanced by converting all household members into their adult equivalent employing standard conversion table.

The methodology of classifying a given household as food secure or food insecure depends on the minimum acceptable weighted average food requirement of 2100 kcal per adult equivalent per day which is estimated to be $225 \mathrm{~kg}$ of food (grain equivalent per person per year) set by the Ethiopian government. As a result, total kcal consumed by a given household during the past seven days were computed for daily consumption and finally divided by total household adult equivalent to reach a kcal per adult equivalent per day.

Having identified the food insecure and food secure groups of households, the next step was to identify the socio-economic characteristics that are correlated with food insecurity. In light of this, it was hypothesized that household characteristics such as sex of household head, household size, access to credit, daily income per adult equivalent, proportion of household food expenditure, household head education status, dependency ratio, owning savings account and marital status of household head have relative importance in determining the state of food security at household level.

In order to test the hypothesis, a probabilistic model is specified with food security as a function of series of household characteristics as explanatory variables. The dependent variable in this case is dummy variable, which takes a value of zero or one depending on whether or not a household is food insecure.

Thus, a logistic model was specified to identify the determinants of food insecurity and to assess their relative importance in determining the probability of being in a food insecure situation at household level. Pertinent to the above statements and following Gujarati (1995), the functional form of logit model can be specified as:

$$
P_{i}=E\left(Y=1 / X_{i}\right)=\frac{1}{1+e^{-\left(\beta_{o}+\beta_{i} X_{i}\right)}}
$$

For ease of exposition, we write (1) as:

$$
\mathrm{P}_{\mathrm{i}}=\frac{1}{1+\mathrm{e}^{-\mathrm{Z}_{\mathrm{i}}}}
$$

The probability that a given household is food insecure is expressed by (2) while the probability for not food insecure is:

$$
1-P_{i}=\frac{1}{1+e^{Z_{i}}}
$$

Therefore, we can write:

$$
\frac{P_{i}}{1-P_{i}}=\frac{1+e^{Z_{i}}}{1+e^{-Z_{i}}}
$$

Now, (Pi/1-Pi) is the ratio of the probability that a household will be food insecure to the probability of that it will not be food insecure. More specifically, it 
represents simply the odds ratio in favor of food insecurity.

Finally, taking the natural $\log$ of equation (4), we obtain:

$\mathrm{L}_{\mathrm{i}}=\ln \left[\frac{\mathrm{P}_{\mathrm{i}}}{1-\mathrm{P}}\right]=\mathrm{Z}_{\mathrm{i}}=\beta_{\mathrm{o}}+\beta_{1} \mathrm{X}_{1}+\beta_{2} \mathrm{X}_{2}+\ldots+\beta_{\mathrm{n}} \mathrm{X}_{\mathrm{n}----}(5)$

where, $P i$ is a probability that household $i$ of being food insecure and ranges from 0 to $1 ; Z i$ is a function of $\mathrm{n}$ explanatory variables $(\mathrm{X})$ which can also be expressed as:

$$
\mathrm{Z}_{\mathrm{i}}=\beta_{\mathrm{o}}+\beta_{1} \mathrm{X}_{1}+\beta_{2} \mathrm{X}_{2}+\ldots+\beta_{\mathrm{n}} \mathrm{X}_{\mathrm{n}}
$$

where, $\beta_{0}$ is an intercept, $\beta_{1}, \beta_{2}, \ldots, \beta_{\mathrm{n}}$ are slopes of the equation in the model, $L i$ is $\log$ of the odds ratio, which is not only linear in $\mathrm{X}_{\mathrm{i}}$ but also linear in the parameters, and $X i$ is vector of relevant household characteristics.

If the disturbance term $\left(\mathrm{U}_{\mathrm{i}}\right)$ is introduced, the logit model becomes:

$$
\mathrm{Z}_{\mathrm{i}}=\beta_{\mathrm{o}}+\beta_{1} \mathrm{X}_{1}+\beta_{2} \mathrm{X}_{2}+\ldots+\beta_{\mathrm{n}} \mathrm{X}_{\mathrm{n}}+\mathrm{U}_{\mathrm{i}-\mathrm{-}}(7)
$$

To scrutinize the dimensions of food insecurity, head count ratio, food insecurity gap and severity of household food insecurity have been estimated employing the Foster, Greer and Thorbecke (FGT) index (Foster, Greer and Thorbecke, 1984). This model was recently used by the International Food Policy Research Institute (IFPRI) for the analysis of household food insecurity (Hoddinott, 2001).

The FGT model can be expressed as follows:

$$
P(\alpha)=1 / n \sum_{i=1}^{q}\left[\left(m-y_{i}\right) / m\right]^{\alpha}
$$

where, $\mathrm{n}$ is the number of sample households, $y_{i}$ is the measure of per adult equivalent food calorie intake of the $i^{\text {th }}$ household, $m$ represents the cutoff between food security and insecurity (expressed in caloric requirement), $\mathrm{q}$ is the number of food insecure households, and $\alpha$ is the weight attached to the severity of food insecurity. In equation (8), $\mathrm{m}-\mathrm{y}_{\mathrm{i}}=0$ if $\mathrm{y}_{\mathrm{i}}>\mathrm{m}$.

Attaching no weight to the severity of food insecurity is equivalent to assuming that $\alpha=0$. So then, the formula reduces to $P(0)=q / n$, this is called the head count ratio and measures the proportion of sample households which are deemed to be food insecure. Giving equal weight to the severity of food insecurity among all food insecure households is equivalent to assuming that $\alpha=1$. Summing the numerator gives the food insecurity gap; dividing this by $\mathrm{m}$ expresses this figure as a ratio. This index $\mathrm{P}(1)$ will provide the opportunity to estimate resources required to eliminate food insecurity through proper targeting. That is, the product $\left(\mathrm{n}^{*} \mathrm{~m} * \mathrm{P} 1\right)$ gives the total calorie commitment required to bring the food insecure households to the given daily calorie requirement level.

In addition, giving weight to the severity of food insecurity among the most food insecure households is equivalent to assuming that $\alpha>1$. The most common approach in poverty literature is to set $\alpha=2$, yielding:

$$
P(2)=1 / n \sum_{i=1}^{q}\left[\left(m-y_{i}\right) / m\right]^{2}
$$

Hence, $\mathrm{P}(0)$ measures percentage of food insecure households, $\mathrm{P}(1)$ is food insecurity gap and $\mathrm{P}(2)$ is the severity of food insecurity.

\section{Results and Discussion}

\subsection{Household Food Security Status and Adult} Equivalent

Family size in terms of adult equivalent (AE) and food insecurity are related positively. The number of adult equivalents within the household does not necessarily imply job opportunities or access to income and the same was reflected in the survey result.

Households with less than 3.51 adult equivalents constituted $54.4 \%$ of food secure and $29 \%$ of food insecure households. Similarly, $55.8 \%$ of food insecure and $34.2 \%$ of food secure households have AE within a range of 3.51-6.00. A significant mean difference of adult equivalent was revealed in the survey results between the two groups at probability level of less than 1\% (Table 1).

Table 1. Household food security and adult equivalent.

\begin{tabular}{lrrr}
\hline Adult equivalent group & Food secure $(\mathrm{N}=114)$ & Food insecure $(\mathrm{N}=86)$ & Total $(\mathrm{N}=200)$ \\
\hline & \multicolumn{3}{c}{ Percent } \\
\cline { 2 - 5 }$\leq 3.50$ & 54.40 & 29.00 & 43.50 \\
$3.51-6.00$ & 34.20 & 55.80 & 43.50 \\
$6.01-8.50$ & 11.40 & 10.50 & 11.00 \\
$\geq 8.51$ & 0.00 & 4.70 & 2.00 \\
\hline Mean (AE) & 3.77 & 4.51 & 4.09 \\
Std. Deviation & 1.68 & 1.89 & 1.81 \\
t-value & & $2.880^{* * *}$ & \\
\hline
\end{tabular}

*** $=$ Significant at $P<0.01$

\subsection{Household Food Security and Occupation Categories}

Out of 86 food insecure households, those household heads involved in informal activity, government and unemployed contribute $23.30,30.20$ and $30.20 \%$ of food insecure households, respectively, whereas those involved in formal activity comprised about a quarter of food secure households.

Those household heads classified as unemployed but which are food secure obtain their income from relatives as gift and remittance and some from house rent. Not surprisingly, households whose household heads were employed in NGOs were found to be food secure. The 
result of the survey revealed a significant difference in terms of occupation of household head among the food secure and food insecure groups at less than $1 \%$ probability level (Table 2).

Table 2. Household food security status by occupation categories.

\begin{tabular}{lrrrr}
\hline Occupation category & Food secure $(\mathrm{N}=114)$ & Food insecure $(\mathrm{N}=86)$ & Total $(\mathrm{N}=200)$ & $\chi^{2}$ \\
\cline { 2 - 5 } Formal & \multicolumn{3}{c}{ Percent } & 21.50 \\
Informal & 27.20 & 14.00 & 15.00 \\
Government & 8.80 & 23.30 & 35.00 \\
NGOs & 38.60 & 30.20 & 3.50 \\
Unemployed & 6.10 & 0.00 & 22.50 \\
Others & 16.70 & 30.20 & 2.50 \\
\hline
\end{tabular}

*** $=$ Significant at $P<0.01$

3.3. Household Food Security and Education of Household Head

In societies such as Ethiopia, where household heads are the major breadwinners of the households, the household head's educational status could determine the food security status of the entire household. The survey results showed an insignificant relationship at $10 \%$ probability level when household educational level was categorized into illiterate, write and read, primary, secondary etc and became significant while categorized as literate and illiterate at less than $5 \%$. Categorization of the household head as literate and illiterate exhibited that $77 \%$ of household heads were literate. Among the literate households, $61.7 \%$ were found to be food secure and out of 46 illiterate households, $58.7 \%$ were food insecure (Table 3).

Table 3. Household food security by educational status of household head.

\begin{tabular}{|c|c|c|c|c|}
\hline Level of education & Food secure $(\mathrm{N}=114)$ & Food insecure $(\mathrm{N}=86)$ & Total $(\mathrm{N}=200)$ & $\chi^{2}$ \\
\hline & \multicolumn{3}{|c|}{ Percent } & \\
\hline Illiterate & 16.70 & 31.40 & 23.00 & 12.51 \\
\hline Write and read & 7.90 & 6.98 & 7.50 & \\
\hline Primary, $1^{\text {st }}$ cycle & 5.30 & 6.98 & 6.00 & \\
\hline Primary, $2^{\text {nd }}$ cycle & 14.00 & 19.77 & 16.50 & \\
\hline Secondary, $1^{\text {st }}$ cycle & 8.80 & 4.65 & 7.00 & \\
\hline Secondary, $2^{\text {nd }}$ cycle & 31.60 & 22.00 & 27.50 & \\
\hline Certificate & 1.70 & 1.16 & 1.50 & \\
\hline Diploma & 10.50 & 6.98 & 9.00 & \\
\hline $\mathrm{BSc} / \mathrm{BA}$ and above & 3.50 & 0.00 & 2.00 & \\
\hline Literate & 61.70 & 38.30 & 77.00 & $6.005^{* *}$ \\
\hline Illiterate & 41.30 & 58.70 & 23.00 & \\
\hline Total & 57.00 & 43.00 & 100.00 & \\
\hline
\end{tabular}

** $=$ Significant at $P<0.05$

The possible implication is that, in addition to other factors, while some level of education is important to household food security, its marginal contribution beyond primary education is small unless continued further or supported by vocational training that enable households to be self employed or competent to be employed.

\subsection{Household Food Security Status by Number of Income Sources}

The sampled households reported that $64 \%$ of them had engaged in one to two income-generating activities. Diversifying income sources is important to reduce risk in the urban economic environment, especially for low income groups. The average number of income generating activities or sources per household for the whole sample was found to be 2.3. The corresponding figures for food secure and food insecure were found to be 2.16 and 2.5, respectively. The reasons for higher mean of income sources for food insecure households might be associated with the type of activity households had been engaged in and the insufficiency of income to cover household's food and non-food expenditure.

It was hypothesized that number of income sources and food insecurity were related negatively. Within the food insecure group, the higher the number of income sources, the lower the percentage of food insecure households. The number of income sources exhibited a significant mean difference at less than 5\% probability level between the two groups (Table 4). 
Table 4. Household food security by number of income sources.

\begin{tabular}{lrrr}
\hline Number of income sources & Food secure $(\mathrm{N}=114)$ & Food insecure $(\mathrm{N}=86)$ & Total $(\mathrm{N}=200)$ \\
\hline & \multicolumn{3}{c}{ Percent } \\
$1-2$ & 71.00 & 54.70 & 64.00 \\
$3-4$ & 24.60 & 37.20 & 30.00 \\
$5-6$ & 4.40 & 8.10 & 6.00 \\
\hline Mean & 2.16 & 2.50 & 2.30 \\
\hline Standard deviation & 1.07 & 1.22 & 1.15 \\
t-value & & $2.096^{* * *}$ & \\
\hline$* * *$ Sigmificant at $P<0.01$ & & &
\end{tabular}

*** $=$ Significant at $P<0.01$

3.5. Household food security and daily income per adult equivalent

Household income is of paramount importance in achieving household food security, especially in the urban situation where people largely depend on earning capacity rather than on natural resources as in rural areas.

Daily income per adult equivalent was hypothesized to have a negative relationship with household food insecurity. About $16 \%$ of food secure and $38.4 \%$ of food insecure households were found to earn a daily income per adult equivalent of Birr 4 or less. Hence, as daily income per AE increases, the percentage of food insecure households exhibits a declining tendency. The mean daily income per adult equivalent of food secure and food insecure households were found to be Birr 16.73 and 6.93, respectively. The survey results depicted a significant mean difference in daily income per adult equivalent at probability level of less than 1\% between food secure and food insecure household groups (Table 5).

Table 5. Household food security status by daily income per adult equivalent (Birr).

\begin{tabular}{lrrr}
\hline Daily income per adult equivalent & Food secure $(\mathrm{N}=114)$ & Food insecure $(\mathrm{N}=86)$ & Total $(\mathrm{N}=200)$ \\
\cline { 2 - 5 }$\leq 4.00$ & \multicolumn{3}{c}{ Percent } \\
$4.01-8$ & 15.79 & 38.37 & 25.50 \\
$8.01-12$ & 18.42 & 29.07 & 23.00 \\
$12.01-16$ & 21.93 & 19.77 & 21.00 \\
$16.01-20$ & 11.40 & 5.81 & 9.00 \\
$>20$ & 7.89 & 4.65 & 6.50 \\
\hline Mean & 24.56 & 2.33 & 15.00 \\
\hline Standard deviation & 16.73 & 6.93 & 12.51 \\
t-value & 18.80 & 6.30 & 15.54 \\
\hline
\end{tabular}

*** $=$ Significant at $P<0.01$

3.6. Household Food Security and Daily Food Expenditure per Adult Equivalent

Urban food expenditure in the Dire Dawa sample households was characterized by heavy reliance on purchased food commodities such as cereals, pulses, vegetables and livestock products. Food commodity from own production was almost non-existent. The mean daily food expenditure per AE of the whole sample was Birr
4.04 and for food secure and food insecure households, the figures were 5.12 and 2.60, respectively. As the amount of daily food expenditure per AE increased, significant level of difference was observed between the two groups. The results of the survey suggested a significant mean difference in daily food expenditure per $\mathrm{AE}$ at less than $1 \%$ significant level $(P<0.01)$ between the two groups (Table 6).

Table 6. Household food security status by daily food expenditure (Birr).

\begin{tabular}{lrrr}
\hline Daily income per adult equivalent & Food secure $(\mathrm{N}=114)$ & Food insecure $(\mathrm{N}=86)$ & Total $(\mathrm{N}=200)$ \\
\cline { 2 - 5 }$\leq 4.50$ & \multicolumn{3}{c}{ Percent } \\
\cline { 2 - 4 } $4.51-8.00$ & 47.37 & 88.37 & 65.00 \\
$8.01-11.50$ & 40.35 & 10.47 & 27.50 \\
$11.51-15.00$ & 8.77 & 1.16 & 5.50 \\
$\geq 15.01$ & 2.63 & 0.00 & 1.50 \\
Mean & 0.88 & 0.00 & 0.50 \\
\hline Standard deviation & 5.12 & 2.60 & 4.04 \\
t-value & 2.61 & 1.53 & 2.54 \\
\hline
\end{tabular}





\section{Determinants of Food Insecurity}

Nine independent variables that were hypothesized to have influence on household food insecurity in the study area were included in the model, of which seven were found to be statistically significant. The likelihood ratio has a chi-square distribution and it can be used for assessing the significance of logistic regression. It is used to test the null hypothesis that none of the independents are linearly related to the log odds of the dependent. It is an overall model test which does not, however, assure every independent variable is significant. The estimated result was found to be significant at less than $1 \%$ probability level revealing the null hypothesis that none of the independents are linearly related to the log odds of the dependent is rejected. Additionally, goodness of fit in logistic regression analysis is measured by count $\mathrm{R}^{2}$ which works on the principle that, if the predicted probability of the event is greater than 0.50, the event will occur otherwise the event will not occur (Table 7).

Table 7. The maximum likelihood estimates of the logit model.

\begin{tabular}{|c|c|c|c|c|}
\hline Variable code & Variable type and definition & Coefficient & Wald statistics & Odds ratio \\
\hline HSZE & Household size in number & 0.413 & $15.528^{* * *}$ & 1.512 \\
\hline HHSX & Dummy: 1 if household head is male; 0 otherwise & 1.797 & $4.572^{* *}$ & 6.033 \\
\hline MRTSTHH & Dummy: 1 if household head is married; 0 otherwise & -1.472 & $3.327^{*}$ & 0.229 \\
\hline EDUSTHH & Dummy: 1 if household head is literate; 0 otherwise & -1.161 & $5.992^{* *}$ & 0.313 \\
\hline DYINCAE & Daily income per adult equivalent & -0.147 & $18.625^{* * *}$ & 0.863 \\
\hline PRPNFDEX & Proportion of expenditure on food & -0.008 & $3.276^{*}$ & 0.992 \\
\hline HGTCRDT & Dummy: 1 if household has got credit; 0 otherwise & -0.862 & $3.248^{*}$ & 0.422 \\
\hline HSAVACC & Dummy: 1 if household has saving account; 0 otherwise & -0.296 & 0.527 & 0.744 \\
\hline DEPNDRTO & Dependency ratio & -0.156 & 0.262 & 0.855 \\
\hline Constant & & 0.563 & & \\
\hline \multicolumn{2}{|c|}{ Pearson Chi-square } & & $66.67 * * *$ & \\
\hline \multicolumn{2}{|c|}{-2 Log likelihood } & & 206.65 & \\
\hline \multicolumn{2}{|c|}{ Sensitivity } & & 69.80 & \\
\hline \multicolumn{2}{|c|}{ Specificity } & & 78.90 & \\
\hline \multicolumn{2}{|c|}{ Percent correctly predicted (Count $\mathrm{R}^{2}$ ) } & & 75 & \\
\hline \multicolumn{2}{|c|}{ Sample size } & & 200 & \\
\hline
\end{tabular}

*** $=$ Significant at $P<0.01 ; * *=$ Significant at $P<0.05 ; *=$ Significant at $P<0.10$.

Overall, the estimated model correctly predicted $75 \%$ of households to fall into the actual category. The sensitivity, correctly predicted food insecure is $69.8 \%$ and that of specificity, correctly predicted food secure is $78.9 \%$. This indicates that the model has estimated the food insecure and food secure correctly. In light of the above summarized model results, a possible explanation for each significant independent variable is given consecutively as follows:

\subsection{Household Size (HSZE)}

Given the strong positive relationship between household size and food insecurity already noted in the descriptive part, it is not surprising that the estimated parameters are positive and highly significant. This positive relationship shows that the odds ratio in favor of the probability of being food insecure increase with increase in household size. Other things remaining equal, the odds ratio in favor of food insecurity increases by a factor of 1.512 as household size increases by one. The possible reason is that with the existing high rate of unemployment and fewer employment opportunities coupled with low rate of payment, an additional household member shares the limited available resources that lead the household to become food insecure.

\subsection{Sex of Household Head (HHSX)}

Sex of household head is represented by a dummy variable taking the value equal to one if the sample household is headed by male, zero otherwise. The estimated coefficient of the variable is found to be significant at less than $5 \%$ probability level and positively related with household food insecurity. That implies, assuming other variables are kept constant at their mean values; a household headed by a male is more likely to be food insecure compared to female headed households. A possible reason may be that female household heads are more responsible and pay due attention to their family. Therefore, having a woman as head of household implies higher caloric availability due to differences in spending priorities between males and females.

\subsection{Marital Status of Household Head (MRTSTHH)}

It is dummy variable taking a value of one if the household head is married and 0 otherwise The negative relationship with dependent variable is related to the economic scale of consumption items purchased and pooling available resources in one way or another and, possibly, married households reduce expenditure that would have been spent separately. The results of marital status and sex of household seems to be contradictory but headship is not only gifted to male as observed from sampled households. There were female household heads in the presence of male (husband) either due to economic reasons or absence of male household head in the area for any reasons. In general, being married in itself is not an assurance of escape from the risk of food insecurity. Rather, it is mainly because of the fact that household size, level of income and other factors of household affect food security status in relation to marital status. 


\subsection{Educational Status of Household Head (EDUSTHH)}

Although the educational status of other income earner household members is of great importance, that of the household head plays a significant role in shaping household members by being exemplary and willing to invest in education. The negative coefficient for education can be explained in terms of contribution to education on working efficiency, competency, diversifying income, adopting technologies and becoming visionary in creating a conducive environment to educate dependants with the long term target of ensuring better living conditions than illiterate ones. Thus, being literate reduces the chance of becoming food insecure in the sample households.

\subsection{Daily Income per Adult Equivalent (DYINCPAE)}

The survey results showed a negative relation between daily income per adult equivalent and food insecurity and the coefficient is highly significant at less than $1 \%$ probability level. It corresponds with the prior expectation and the explanation is that income determines purchasing power of the household with the prevailing price so that those households with higher daily income per adult equivalent are less likely to become food insecure than low income households.

\subsection{Proportion of Food Expenditure (PRPNFDEX)}

Proportion of food expenditure spent by the household is significant at less than $10 \%$ probability level and related negatively with food insecurity. Given that other variables are held constant, as the proportion of expenditure on food increases, access to food by household also increases to the amount needed for household consumption. In the situation where some covariant shocks, happen, for instance rise in price of food commodity increasing the proportion on food expenditure helps to overcome the change and keep households accessing needed food and it also leads to the consumption of better quality food.

\subsection{Household Access to Credit (HGTCRDT)}

The results of the survey revealed that the variable under consideration is negatively related to food insecurity and significant at less than $10 \%$ probability level. The possible explanation is that credit gives the household an opportunity to be involved in income generating activities so that derived revenue increases financial capacity and purchasing power of the household to escape from the risk of food insecurity. Access to credit also supports consumption when households face hard times.

\section{Extent and Severity of Food Insecurity}

The results of the survey revealed that the head count ratio or incidence of food insecurity is 0.43 which implies that $43 \%$ of the sampled households cannot meet the daily recommended caloric requirement. The food insecurity gap was computed to discover how far the food insecure households are below the recommended daily caloric requirement and also provides the opportunity of to estimating resources required to eliminate food insecurity through proper targeting. The food insecurity gap was found to be 0.13 which indicates that, if the city administration mobilizes and distributes resources that can meet $13 \%$ of the caloric needs of every food insecure household and distribute to each household to bring it up to the recommended daily caloric requirement level, then theoretically, food insecurity could be eliminated. Finally, the severity of food insecurity, for the most food insecure households was found to be 0.059 .

\section{Summary and Policy Implications}

The sample households were classified into food secure and food insecure groups based on kcal actually consumed by the households during the previous seven days of survey date compared with the recommended daily kcal per adult equivalent. Total daily food energy per adult equivalent of less than $2100 \mathrm{kcal}$ was considered as food insecure and food secure otherwise.

The descriptive statistics showed the existence of a significant mean difference in daily income per AE and daily food expenditure per AE at less than 1\% probability level between food secure and insecure households. The t-test for household adult equivalent showed a mean difference between the two groups at less than $1 \%$ probability level, but less than 5\% significance level for number of income sources. Education status and occupation of household head were found to be significant at less than 5 and $1 \%$ significance levels, respectively.

Binary logit model output showed that seven out of nine variables, namely household size, sex of household head, marital status of household head, education of household head, daily income per adult equivalent, proportion of food expenditure and access to credit were found to be statistically significant with the hypothesized sign as determinants of household food insecurity in the study area.

The head count ratio revealed that $43 \%$ of sampled households were found to be food insecure. The gap and severity of food insecurity were estimated to be 13 and $5.9 \%$, respectively.

Even if limited in scope and with a lot of questions remaining unanswered, this study has come up with results which have important policy implications. The relatively stagnant business condition coupled with poor investment performance in the study area has contributed to the deterioration of income generation capacity for food insecure households. In this situation, household size aggravates the problem of meeting food requirements. Therefore, action-based awareness creation on the impacts of population growth at the family, community and national levels should be strongly advocated in an attempt to reduce fertility and lengthen birth spacing. Moreover, development actors involved in the population issue should encourage households to have an acceptable number of children through provision of support such as covering schooling costs, providing training and other related incentives. 
Furthermore, as income and food insecurity are negatively related, searching for and providing productive technical skills to make trainees competitive on the current labor market and able to generate income should be sought and promoted. Moreover, the administrative council should also consider the reallocation and utilization of food security program budgets for the purpose of employment generation schemes in urban Dire Dawa. Access to credit could also create an opportunity to be involved in economic activity that generates revenue to households. Development partners operating in the study area should provide credit to eligible households using targeting criterion that reflects actual characteristics of food insecure households. The other pressing issue related to provision of credit is the requirement of collateral and group lending procedures, which discourages so many households. People are afraid of holding accountability for others so individual lending should be considered as another option and collateral requirement should be avoided since there is a need to lift food insecure households out of their current situation. Simultaneously, borrowers should be encouraged to save or contribute as matching fund to reach the limited resources for a large number of needy people.

The effect of education on household food security reveals the significant role of the variable in consideration for betterment of living conditions. The more the household head is educated, the higher will be the probability of educating other family members too, so that they become familiar with modern technology, which the twenty first century badly demands. Therefore, strengthening both formal and informal education and vocational or skills training should be promoted to reduce food insecurity in Dire Dawa town.

\section{References}

Chung, K., Haddad, L., Ramakrishna, J. and Eiley, F. 1997. Identifying the Food Insecure: The application of mixed method approach in India. International Food Policy Research Institute, Washington, D.C.

CSA (Central Statistical Authority). 1999. Population and housing census for Ethiopia. Results for Dire Dawa Administration. Volume II. Analytical Report. Addis Ababa, Ethiopia.

CSA (Central Statistical Authority). 2004. Report on urban bi-annual employment survey. First Year Round 2. Statistical Bulletin 319. Addis Ababa, Ethiopia.

EHNRI (Ethiopian Health and Nutrition Research Institute). 1998. Food composition table for use in Ethiopia. Part III and IV. Addis Ababa, Ethiopia.
Engle, P., Ruel, M.T., Garrett, J.L., Morris, S.S., Maxwell, D., Oshaug, A., Menon, P., Slack, A. and Haddad, L. 1998. Urban challenges to food and nutrition security: A Review of Food Security, Health and Caregiving in Cities. Food Consumption and Nutrition Division. Discussion Paper No 51. International Food Policy Research Institute, Washington, D.C.

FDRE (Federal Democratic Republic of Ethiopia). 2002. Sustainable development and poverty reduction Program. Addis Ababa, Ethiopia.

Foster, J., Greer, J. and Thorbecke, E. 1984. A class of decomposable poverty measures. Econometrica 52: 761-765.

Gujarati, D.N. 1995. Basic Econometrics. $3^{\text {rd }}$ edition. McGraw - Hill Co. New York.

Habicht, J.P. and Pelletier, D.L. 1990. The importance of context in choosing nutritional indicators. Journal of Nutrition 120 (11): 1519-1524.

Hoddinott, J. 2001. Methods for rural development projects. Food Security in Practice. International Food Policy Research Institute, Washington, D.C.

Kennedy, E., Payongayong, E., Haddad, L., Tshibaka, T., Agble, R. and Tetebo, R. 1994. Impacts of credit programs on food security and nutrition in Ghana. International Food Policy Research Institute, Washington, D.C.

Maxwell, D., Levin, C., Armar-Klemesu, M., Ruel, M., Morris, S. and Ahiadeke, C. 2000. Urban livelihood and food and nutrition security in Greater Accra, Ghana. Research Report No. 112. International Food Policy Research Institute, Washington, D.C.

Maxwell, S. 1996. Food security: A post-modern perspective. Food Policy 21(2): 155 - 170.

Maxwell, S. and Frankenberger, T.R. 1992. Household food security: A Conceptual Review. Household Food Security: Concepts, Indicators, Measurements. A Technical Review. IFAD/UNICEF. New York and Rome.

MoFED (Ministry of Finance and Economic Development). 2002. Development and poverty profile of Ethiopia. Welfare Monitoring Unit, Addis Ababa, Ethiopia.

MoPED (Ministry of Planning and Economic Development). 1994. Report on household food security study of four towns. Food and Nutrition Unit, Addis Ababa, Ethiopia.

Payne, P. R. 1990. Themes in food security: Measuring malnutrition. IDS Bulletin 21 (3): 14-30. 